\title{
Stimulation of innate immunity with non-specific methods
}

\author{
Csaba G* \\ Department of Genetics, Cell- and Immunobiology, Semmelweis University, Budapest, Hungary
}

\begin{abstract}
Although the human activity produces plethora of new specific drugs and methods against different diseases, considering the possibilities of the organism's immune system, there are such situations when the adaptive immune system is not able to wrestle with the attack of an infection as there were not vaccination for it. In such case the non-specific (innate) immune system can help. For its successful function stimulatory molecules could be needed. These are certain vitamins (A, C, D, E), trace elements (zinc and selenium) and some essential oils. Using them in higher than ordinary amounts (megadoses), vitamins leave the food supplementary category and step over the medicament (drug) class. In this quality they could help to overcome viral diseases. This means that vitamins as a need for normal life in minute doses and vitamins as drugs (in megadoses to rev up the innate immune system) for healing must be separated in the medical frame of mind.
\end{abstract}

This manuscript was born in the time, when world epidemic (pandemic) of the new corona-virus (COVID-19) caused problems, as there were not man-made or natural chemicals which would have been able to defend man from the harmful and sometimes killer effect of the virus, so all methods have to be considered for thinking by which the effect of virus can be restricted or eliminated.

\section{The human immune system}

The immune system of man- as in general the vertebrate immune system- has two different parts, the innate (non-specific) and adaptive (specific) immune system with different kinds of cells and tasks. The innate system is more archeal, more primitive, which serves general immune functions: it recognizes and discriminates self from non-self while defends the self, tries to terminate and destroy or eliminate the non-self (independent on the usefulness or harmfulness of the action (as it does happen e.g. in case of heterotransplantation). It is in the first line of defence using its macrophages and monocytes as well as natural killer (NKly) cells. Considering earlier (old) theories it does not have memory however, animals without adaptive immune system showed some signs of immune memory. Seeking the reason of this event the trained memory concept was established and the memory of the nonspecific innate system had been justified [1-4]. The more developed adaptive immune system has memory, by which it recognizes such molecules (antigens) with which it encountered previously and attacks them. This is the basis of vaccination, which does not permit the presence or proliferation of strange (non-self) cells (microbes, viruses, parazites) or their solved antigens in the organism. After vaccination the organism is defended to the pathogenic effects of them. In many cases there are vaccines against pathogenic viruses and the adaptive immune system is working well, however the function of innate immune system is needed when the antigen was not previously memorized.

Both immune systems could be stimulated by certain molecules among which some vitamins and trace elements and essential oils are the most known and most proved.

\section{Vitamins}

Vitamins have been discovered in case of diseases, where the deficiency of them caused the disease and the supplementation of the vitamin given justified the interrelation between the disease and vitamin. Characteristic example of this, is the treatment of scurvy by vitamin $\mathrm{C}$ and cod-liver oil prevention of rachitis. However this does not mean, that this interrelation exhausts each function of the vitamin and it seems likely, that the physiological role of certain vitamins is more important and more comprehensive, than the healing of the previously mentioned target-disease.

Vitamin-A retinol, It is lipid-soluble, so can be accumulated in the human organism, what means that dosage must be cautious. It has a basic role in vision, its deficiency leads to night-blindness. It is necessary for the function of immune system, its presence stimulates, deficiency weakens the innate immunity $[5,6]$ Retinoids influence the differentiation of lymphocytes, the antibody production and phagocytosis by macrophages, the NKly, Treg, and T-helper cell's activity. Animal experiments show that vitamin A deficiency is associated with immune system defect.

Vitamin-C About 50 years ago the Nobel-prize owner Linus Pauling called the attention to vitamin-C (ascorbic acid), as an immune-stimulant in case of respiratory illnesses and since this time many statistical analyses have been done. The results partly justified Pauling's observations and commendations partly denied them [7]. Common cold or influenza were (are) the model-diseases by which the effect of vitamins could be studied, and in case of hypovitaminosis- $\mathrm{C}$ the common cold and also influenza became more serious and their duration was longer [8]. At the same time, preventively used C-vitamin treatment with megadoses reduced the infectivity and duration $[9,10]$ of these diseases. This was justified at first by Pauling itself and others after him. Here must be emphasised the dose, as it is recommended by authorities, which is suitable for the prevention of scurvy, which was

*Correspondence to: György Csaba, Department of Genetics, Cell- and Immunobiology, Semmelweis University, Budapest, Hungary, E-mail: csaba. gyorgy@med.semmelweis-univ.hu

Received: February 15, 2020; Accepted: February 25, 2020; Published: February 29,2020 
employed when the discovery happened which could be consumed of citrus fruits or cabbage, however for the prevention of common cold 1 or $2 \mathrm{~g} /$ day were used, and this decreased the cold duration with $6 \%$ in adults and $26 \%$ in children [11] in contrast to hypovitaminosis which aggravated the severity of the illness and hamper recovery [12]. The megadoses $(1,2 \mathrm{~g} /$ day decreased the severity of illness in $85 \%$ of the common cold and influenza cases [13], especially in children [11]. The vitamin-C megadoses combined with dosage of zinc $(10 \mathrm{mg} /$ day $)$ increased the effect [14]. In case of vitamin-C hypovitaminosis common cold was more sever and durable [8]. Increasing weekly megadoses (from 1 to $3 \mathrm{~g} /$ day) of ascorbic acid stimulated the lymphocyte transforming effect of phytohemagglutinin and concanavalin A.

Vitamin-D. This vitamin is really a steroid hormone (secosteroid) produced by the skin under the influence of sunlight (UV), however it is present in some foods e.g. mushrooms, eggs, meats, milk etc and can be extracted from the liver of cod [15]. This is also antioxidant, as vitamin-C, however it is lipid-soluble in contrast to vitamin-C which is water-soluble, so vitamin $\mathrm{D}$ can save the health of cell membrane components while vitamin $C$ saves the others. It was recognized as antirachitic vitamin however, in case of deficiency the sensitivity to infectious diseases enhances because of impaired local immunity and defects of cellular immune response. It has a basic role in the activation of innate immunity $[16,17]$. Macrophages, dendritic cells, $\mathrm{T}$ and $\mathrm{B}$ lymphocytes have vitamin-D receptor and the enzyme needed for the conversion of circulating vitamin-D into its active form [18,19]. It has an important role in the control of immunity of upper respiratory tracts, and enhances two antimicrobial peptides (defensine and cathelicidine) production [20]. There is an inverse non-linear connection between the acute respiratory infections and the blood concentration of vitamin D $[21,22]$. Its deficiency increases the number of respiratory infections [23-26]. Its megadoses around $1000 \mathrm{IU} /$ day or more have been used for prevention in case of people exposed to respiratory infections. Bronchial epithelial cells have antiviral activity in vitro and vitamin-D increases this activity [27]. However, (as a lipid soluble material) it is accumulated in the organism and overdosage can be occurred.

Vitamin-E. (tocopherol) is also a lipid-soluble antioxidant. Its effect touches practically all immune cells $[28,29]$. It decreases the occurrence and duration of respiratory diseases in elderlies with about $30 \%$. Its deficiency depresses immune functions, which can be influenced by substitution. It increases the efficiency of immune system, mainly in elderlies [30,31].

\section{Trace elements}

Zinc and selenium are metal-like microelements which can be found in the human organism in minimal amount. Zinc decreases the occurrence and duration of common cold, by regulating the whole immune system in a positive direction [32-36]. In the deficiency of selene the influenza virus transformed to a strain with enhanced pathogenicity, while its excess increases the chance of healing virus diseases. Combined dosage of zinc and selenium conduce the function of immune cells [32-36]. Substitution of zink for months increases the antiinfectious immunoresistance. While zink decreased the phagocytic activity of leukocytes, increased their killer-capacity.

\section{Volatile oils}

Eucalyptus essential oil promoted innate cell mediated immune response [37]. The therapeutic potential of medicinal plants against common viral diseases was studied and Sambucus nigra, Caesalpinia pulcherrima and Hypericum connatum had promising specific antiviral activities [38]. In another study Mexican Oregano oil, and its major component carvacrol was efficient in the inhibition of different human and animal viruses [39-41]. Selected monoterpenes from eucaliptus and thymus exhibited high anti-herpes virus activity [42]. Several essential oils had antiviral activity in case of RNA and DNA viruses (such as herpes simplex virus (HSV 1 and 2), influenza and polio virus [43]. Among 250 essential oils which are commercially available about a dozen had antimicrobial potential [44]. Eucalyptus leaf essential oil or D-limonene influence immune cell activity and viability $[45,46]$. More than 300 eucalyptus species contain essential oils, and many of them have antimicrobial activity [46]. D-limonene, a cyclic terpene is the main component of eucalyptus oil which has an immunomodulatory activity [45].

\section{Conclusions}

Considering the above-mentioned data it is obvious that there are such molecules among the mentioned, which can help the defence against such infectious agents, which avoid the specific defence of adaptive immunity however, the mechanism of the effects by these molecules are not completely cleared. As the employment of them beside cautious control- seems to be harmless, worthwhile to prove some of them in case of emergency. Nevertheless in a long run also worthwhile to study the combined effects, the effect of further members of the groups, and similar natural or synthetic molecules. Innate immunity could be not only a saviour in case of absence of adaptive immunity, but its function is needed in the support of adaptive immunity and this aspect is undeservedly neglected.

The selected data clearly show that there are such molecules which act against the proliferation and infectivity of viruses however, their effects are not completely cleared. These molecules must be applied in megadoses, in which they are effective and in this case they are not food-supplements but medicaments (drugs). They are mostly harmless in megadoses, which means that there is not a possibility of overdosing (except lipid soluble vitamins where the gain/hazard ratio must be considered). Previously vitamin C was emploied in a minimal dose which was suitable to avoid scurvy however our modern age which is filled with hormone-like chemicals (endocrine disruptors) requests the elevation of these microdoses to megadoses which are not present in suitable amount in the normal nourishments. The state of certain diseases rather requests the dosage to megadoses which seems to be terrible, however harmless. There are likely no data on the vitamin content of fruits and vegetables of ancient times however, it seems to be sure that freshly picked fruits contained extremely more vitamins than its present-day partner consumed after weeks of transport, cooling, etc. This means that not only the request changed (because of the contamination of environment), but also the quality of goods, which must be supplemented. In addition, the drastic elevation of dose (megadose) means that vitamins (as well, as trace elements) became medicaments which basically changes the mentality of doctors to them. In the case of certain vitamins (as e.g. vitamin-C) presently pharmacological dosesbelieved amount of medically disdained molecules (food supplements) could be common and practitioners difficultly tolerate such change of mentality. However, cultural evolution of man always brings up new questions [47] and in the interest of solution, application of new methods are needed $[48,49]$.

All tools can be used for avoiding illness. Vitamins and trace elements can be used internally and combined, and at the same time volatile oils can be used externally (e.g.in soaps for handwash). Clean (separated) studies are needed for scientific observations however, the armoury of tools together must be permitted in case of emergency. 


\section{References}

1. Netea MG (2013) Training innate immunity: The changing concept of immunological memory in the innate host defence. Eur J Clin Invest 43: 881-884. [Crossref]

2. Netea MG, Quintin J, van der Meer JWM (2011) Trained immunity: A memory for innate host. Cell Host Microbe 9: 355-361. [Crossref]

3. Romo MR, Martinez DP, Castillo Ferrer C (2016) Innate immunity in vertebrates: An overview. Immunology 148: 125-139.

4. Netea MG, Joosten LAB, Latz E, Mills KHG (2016) Trained immunity: A program of innate immune memory in health and disease. Science 352: 1098.

5. Spinas E, Saggini A, Kritas SK, Cerulli G (2015) Can vitamin A mediate immunity and inflammation? J Biol Regul Homeost Agents 29: 1-6.

6. Smith SM, Levy NS, Hayes CE (1987) Impaired immunity in vitamin A- deficien mice. J Nutr 117: 857-865.

7. Edsall JT (1972) Linus Pauling and Vitamin C. Science 178: 696

8. Johnston CS, Barkyoumb GM, Schumacher SS (2014) Vitamin C supplementation slightly improves physical activity levels and reduces cold incidence in men with marginal vitamin C status: a randomized controlled trial. Nutrients 6: 2572- 2583 . [Crossref]

9. Douglas RM, Hemila H, D'Souza R, Chalker EB (2004) Vitamin C for preventing and treating the common cold. Cochrane Database Syst Rev 4

10. Carr AC, Maggini S (2017) Vitamin C and immune function. Nutrients 9.

11. Hemila H (1999) Vitamin C supplementation and common cold symptoms: Factors affecting the magnitude of the benefit. Med Hypotheses 52: 171-178.

12. Spoelstra-de Man A, Elbers PWG, Oudemans-Van Straaten HM (2018) Vitamin C: Should we supplement? Curr Opin Crit Care 224: 248-255.

13. Hemila H (1994) Does Vitamin C alleviate the symptoms of the common cold?-A review of current evidence. Scand J Infect Dis 26: 1-6.

14. Maggini S, Beveridge S, Suter M (2012) A combination of high-dose vitamin C plus zinc for the common cold. $J$ Int Med Res 40: 28-42.

15. Black L, Lucas RM, Sheriff JL, Björn LO (2017) In pursuit of vitamin D in plants. Nutrients 9 .

16. Laaksi I (2012) Vitamin D and respiratory infection in adults. Proc Nutr Soc 71: 90-97.

17. Bartley J (2010) Vitamin D: emerging roles in infection and immunity. Expert Rev Anti Infect Ther 8: 1359-1369. [Crossref]

18. Kikuta J, Ishii M (2015) Current topics on vitamin D. The effects of vitamin D on the immune system. Clin Calcium 25: 359-365.

19. Korf H, Decallone B, Mathieu C (2014) Vitamin D for infections. Curr Opin Endocrino Diabetes Obes 21: 431-436.

20. Bartley J (2010) Vitamin D, innate immunity and upper respiratory tract infection. $J$ Laryngol Otol 124: 465-469.

21. Pham H, Rahman A, Majidi A, Waterhouse M (2019) Acute respiratory tract infection and 25-hydroxyvitamin D concentration: A systematic review and meta analysis. Int $J$ Environ Res Public Health 16

22. Laaksi I, Pentti Tuohimaa JPR, Auvinen A, Haataja A (2007) An association of serum vitamin $\mathrm{D}$ concentrations $<40 \mathrm{nmol} / \mathrm{L}$ with acute res piratory tract infection in young Finnish men. Am J Clin Nutr 86: 714-717.

23. Watkins R, Lemonovich TL, Salata R (2015) An update on the association of vitamin D deficiency with common infectious diseases. Can J Physiol Pharmacol 93: 363 368

24. Greiller CL, Martineau AR (2015) Modulation of the immune response to respiratory viruses by vitamin D. Nutrients 7: 4240-4270.
25. Jimenez-Sousa MA, Martinez I, Medrano LM, Fernandez-Rodriguez A (2018) Vitamin $\mathrm{D}$ in human immunodeficiency virus infection: Influence on immunity and disease. Front Immunol 9: 458

26. Pfeffer PE, Hawrilowicz CM (2012) Vitamin D and lung disease. Thorax 67: 1018 1020.

27. Telcian AG, Zdrenghea MT, Edwards MR, Laza-Stanca V (2017) Vitamin D increase the antiviral activity of bronchial epithelial cells in vitro. Antiviral Res 137: 93-101.

28. Lee GY, Nim Han S (2018) The role of vitamin E in immunity. Nutrients 10.

29. Pakmezci D (2011) Vitamin E and immunity. Vitam Horm 86: 179-215.

30. Lewis ED, Meydani SM, Wu D (2019) Regulatory role of vitamin E in the immune system and inflammatioz. IUBMB Life 71: 487-494.

31. Meydani SM, Nim Han S, Harner DH (2004) Vitamin E and respiratory infection in the elderly. Ann N Y Acad Sci 1031: 214-222. [Crossref]

32. Valentiner-Branth P (2012) The effect of zinc therapy on common cold. A survey of Cochrane Review. Ugeskr Laeger 174: 36-38.

33. Gammoh NZ, Rink L (2017) Zinc in infection and inflammation. Nutrients 9.

34. Wintergerst ES, Maggini S, Hornig DH (2006) Immune-enhancing role of vitamin C and zinc and effect of clinical conditions. Ann Nutr Metab 50: 85-94.

35. Steinbrenner H, Al-Quraishy S, Dkhil MA, Wunderlich F (2015) Dietary selenium in adjuvant therapy of viral and bacterial infections. Adv Nutr 6: 73-82.

36. Ferencik M, Ebringer L (2003) Modulatory effects of selenium and zinc on the immune system. Folia Microbiol 48: 417-426.

37. Serafino A, Sinbaldi Vallebona P, Andreola F, Zonfrillo M (2008) Stimulatory effect of Eucalyptus essential oil on innate cell-mediated immune response. BMC Immunol 9: 17.

38. Akram M, Tahir IM, Shah SMA, Mamood Z (2018) Antiviral potential of medicinal plants against HIV, HSV, influenza, hepatitis, and Coxsackievirus: A systematic Review. Phytother Res 32: 811-822. [Crossref]

39. Husnu K, Baser C (2008) Biological and pharmacological activities of carvacrol and carvacrol bearing essential oils. Curr Pharm Des 14: 3106-3119.

40. Cynthia Cristina Arcila-Lozano (2004) Oregano: properties, composition and biologica activity. Arch Latinoam Nutr 54: 100-111.

41. Ribas Pilau M, Alves SH, Weiblen R, Arenhart S (2011) Antiviral activity of the Lippia Graveolens (Mexican Oregano) essental oil and its main compound carvacrol against human and animal viruses. Braz J Microbiol 42: 1616-1624.

42. Astani A, Reichling J, Schnitzler P (2010) Comparative study on the antiviral activity of selected monoterpenes derived from essential oils. Phytother Res 24: 673-679.

43. Tariq S, Wani S, Rasool W, Shafi K (2019) A comprehensive review of the antibacterial, antifungal and antiviral potential of essential oils and their chemical constituent against drug-resistant microbial pathogens. Microb Pathog 134: 1035080.

44. Winska K, Maczka W, Liczko JG, Grabarczyk M (2019) Essential oils as antimicrobial agents - myth or real alternative? Molecules 24.

45. Lappas CM, Lappas NT (2012) D-limonene modulates T lymphocyte activity and viability. Cell Immunol 279: 30-41.

46. Dhakad AK, Pandey V, Beg S, Rawat JM (2018) Biological, medicinal and toxicologica significance of Eucalyptus leaf essential oil: a review. J Sci Food Agric 98: 833-848.

47. Csaba G (2007) Thoughts on the cultural evolution of man. Developmental imprinting and transgenerational effect. Riv Biol 100: 461-474.

48. Csaba G (2019) Immunity and longevity. Acta Microbiol Immunol Hung 66, 1-17.

49. Csaba G (2018) Possibilities for polonging human lifespan. Orv Hetil 159: 1655 1663.

Copyright: (C2020 Csaba G. This is an open-access article distributed under the terms of the Creative Commons Attribution License, which permits unrestricted use, distribution, and reproduction in any medium, provided the original author and source are credited. 